\title{
Stroke patients' knowledge about cardiovascular family history - the Norwegian Stroke in the Young Study (NOR-SYS)
}

Halvor Øygarden ${ }^{1,2^{*}}$, Annette Fromm ${ }^{1,2}$, Kristin Modalsli Sand ${ }^{1}$, Geir Egil Eide ${ }^{3,4}$, Lars Thomassen ${ }^{1,2}$, Halvor Naess ${ }^{1,2}$ and Ulrike Waje-Andreassen ${ }^{2}$

\begin{abstract}
Background: Family history (FH) is a risk factor for cardiovascular disease, especially coronary artery disease (CAD). The impact on risk of stroke is less clear. This study investigated young and middle-aged ischemic stroke patients' knowledge on FH of stroke, CAD, and peripheral artery disease (PAD) with a special regard to sex differences.

Methods: From September 2010 to February 2014, all ischemic stroke patients aged 15-60 years were prospectively included in the Norwegian Stroke in the Young Study (NOR-SYS). FH of stroke, CAD and PAD in offspring, siblings, parents, and grandparents was assessed using a standardized face-to-face interview. In addition to 'yes' and 'no', the optional reply 'don't know' was included to improve accuracy. McNemar's test was used to compare paired proportions, i.e. FH in male vs. female relatives. Multiple logistic regression analyses were used to test the influence of patient sex on FH reporting and to adjust for possible confounding factors.

Results: Altogether 257 patients were included. Mean age was 49.5 years and $68.1 \%$ were males. FH of cardiovascular disease was reported by 59\% of patients. When asked about FH of stroke, 48 (18.7\%) and 46 (17.9\%) patients reported yes, whereas $17(6.6 \%)$ and 9 (3.5\%) reported 'don't know' regarding father and mother respectively, similarly patients reported 'don't know' regarding 117 (45.5\%) paternal vs. 83 (32.4\%) maternal grandmothers $(p<0.001)$. Female patients reported less 'don't know' and were more likely to report a positive cardiovascular FH than males (OR: 3.4; $95 \% \mathrm{Cl}: 1.5$ to $7.7 ; \mathrm{p}=0.004$ ). Patients had more detailed knowledge about CAD than stroke in fathers $(p<0.001)$, mothers $(p<0.001)$ and siblings $(p=0.01)$.

Conclusions: Young and middle-aged stroke patients reported a high FH burden of cardiovascular disease. Females are more likely to report a positive FH than males. Detailed knowledge on FH was best for CAD. Our results suggest sex has a big impact on FH knowledge. Females have more knowledge of $\mathrm{FH}$ than males and knowledge is better for relatives with a female than male linkage.
\end{abstract}

Clinical trial registration: http://www.clinicaltrials.gov, unique identifier: NCT01597453.

Keywords: Young stroke, Family history, Ischemic stroke, Cardiovascular disease

\footnotetext{
*Correspondence: havy@helse-bergen.no

'Department of Clinical Medicine, University of Bergen, Bergen, Norway

${ }^{2}$ Department of Neurology, Haukeland University Hospital, N-5021 Bergen,

Norway

Full list of author information is available at the end of the article
}

\section{Ciomed Central}

(c) 2015 Øygarden et al.; licensee BioMed Central. This is an Open Access article distributed under the terms of the Creative Commons Attribution License (http://creativecommons.org/licenses/by/4.0), which permits unrestricted use, distribution, and reproduction in any medium, provided the original work is properly credited. The Creative Commons Public Domain Dedication waiver (http://creativecommons.org/publicdomain/zero/1.0/) applies to the data made available in this article, unless otherwise stated. 


\section{Background}

Family history (FH) of cardiovascular disease (CVD) in first-degree relatives (FDRs), including stroke, coronary artery disease (CAD) and peripheral artery disease (PAD), is a risk factor for vascular disease [1,2]. The association between CAD and FH of CVD is well documented [3-6]. However, the impact on risk of ischemic stroke is less clear, although FH of CVD is a positive predictor of stroke risk [7-10]. Sibling and genetic studies support FH of CVD as a risk factor and suggest a genetic influence on ischemic stroke risk [11-13]. Females with stroke are more likely to have a positive parental history than are males, and females are also more likely to have a positive maternal than paternal history $[14,15]$. Why females are more likely to report a positive FH is unknown [16]. Earlier studies of FH in stroke patients seldom separate between $\mathrm{FH}$ of intracranial hemorrhage ( $\mathrm{ICH}$ ) and ischemic stroke, assuming that it would be difficult for patients to differentiate between these [7-9,17-19]. Few studies included a reply of 'don't know' regarding $\mathrm{FH}$, and when included it was usually interpreted as negative, to avoid over-estimating the FH burden [7,9]. However, one study found that $11 \%$ answered 'don't know' regarding FH in FDRs [20]. According to Flossman et al., publications on genetic epidemiology of stroke are heterogeneous, insufficiently detailed and possibly biased [8]. Today, more detailed information about CVD and risk factors is available for patients and their family members. Diagnostic stroke imaging has improved and increased detection of stroke [21]. Repeated efforts to increase awareness of acute stroke symptoms have been implemented after the introduction of thrombolytic therapy [22]. Therefore the public should be better qualified than ever to give a precise account of their $\mathrm{FH}$. As we enter the genomic era of medicine, FH still is the most accessible, inexpensive and well proven tool assessing inherited risk for disease [23].

This population-based study, performed in a welldefined region of western Norway, aims to explore what young and middle-aged ischemic stroke patients know about stroke, CAD and PAD in their families. We aimed to assess and quantify a detailed FH of CVD with a special regard to sex differences.

\section{Methods}

Ischemic stroke patients aged $15-60$ years who were prospectively included in the population-based Norwegian Stroke in the Young Study (NOR-SYS) were assessed. The methods and rationale of NOR-SYS have been described in detail previously [24]. Acute cerebral infarction was documented by magnetic resonance imaging. Patients unable to provide an adequate $\mathrm{FH}$ due to severe stroke, aphasia or severe psychiatric illness, and patients who were adopted or had no contact with their biological family were excluded. This single-center study has Hordaland County as catchment area, from which all patients aged up to 60 years with suspected stroke are admitted to the stroke unit at Haukeland university hospital.

Patients were interviewed using a standardized questionnaire within day two or three after the diagnosis of acute ischemic stroke. The interview was done face to face to ensure the patient did not contact family members by mobile phone or in any other way during the interview; and to ensure only events recalled by the patient were registered. All registration of events was done by the interviewing doctor. To increase reproducibility of answers between study doctors, new interviewers participated as a bystander in at least 5 interviews, thereby increasing the interview similarity and minimizing differences in answer interpretation. Data regarding patient sex, age, education, number of siblings and offspring were registered in addition to a detailed disease history and family history. Patients were assigned to the educational categories, basic school, high school or college/ university education. The three optional replies for the $\mathrm{FH}$ disease entities of stroke, heart disease and PAD/ claudication were: 'yes', 'no' and 'don't know'. 'Don't know' was included to improve accuracy of reporting. The frequency of 'don't know' in FH was also analyzed to assess the effect of patient sex on reporting of FH. In addition, the frequency of 'don't know' was analyzed to assess differences in reporting of maternal vs. paternal $\mathrm{FH}$. The frequency of the answer 'don't know' regarding type of heart and cerebrovascular disease in FDRs was analyzed to compare patients' knowledge on FH of heart disease with their knowledge on cerebrovascular disease. All reported non-CAD, if present without any CAD, was regarded as no CAD. FH of stroke, heart disease and PAD in FDRs; parents, siblings and biological offspring was registered. In addition, $\mathrm{FH}$ of all four grandparents was registered.

To explore in depth knowledge and avoid misinterpretation of disease, further questions were asked. If the patient replied 'yes' regarding FH of any of the disease entities stroke, heart disease and PAD, he was asked to specify the type of stroke or heart disease and in case of PAD he was asked to specify the prescribed treatment. When stroke was reported, the patient was asked to specify the type of stroke as a Transient Ischemic Attack (TIA)/minor stroke with quick and complete restitution, cerebral infarction, ICH or 'don't know'. When heart disease was reported, this was specified as ischemic, such as angina pectoris and myocardial infarction, as non-CAD, such as arrhythmia, valve problem and heart insufficiency or 'don't know'. If PAD/claudication was reported, the patient was asked about the applied 
treatment, such as training, surgical treatment other than amputation, amputation or 'don't know'. If one answer for disease subtype was missing, the data was imputed as 'don't know'.

\section{Statistics}

Descriptive statistics are given using the mean, standard deviation (SD) and proportion with 95\% confidence interval (CI). The chi square test was used for categorical data. McNemar's test was used to compare paired proportions. Continuous and normally distributed variables were analyzed by Student's $t$-test. Wilcoxon's Rank-Sum Test was used to analyze continuous variables that were not normally distributed.

We stratified the patients by sex to compare $\mathrm{FH}$ between males and females. FH of CVD was considered present if at least one parent, sibling or grandparent had CVD. Multiple logistic regression analyses with $\mathrm{FH}$ of CVD as dependent variable and age, sex, educational category and, to adjust for family size, number of siblings as independent variables were performed. The same analyses were performed using FDRs only, to ensure that the high rates of 'don't know' regarding grandparental FH did not affect the main results. The level of significance was set at 0.05. Stata 13.1 (StataCorp, College Station, TX) was used for all analyses.

\section{Ethics}

All patients or legal guardians signed a written informed consent. NOR-SYS is approved by the Regional Ethics Committee of western Norway, and the study was conducted in accordance with the Declaration of Helsinki.

\section{Results}

\section{Demographics}

Between September 2010 and February 2014, 292 stroke patients were included in NOR-SYS. Two patients did not consent, and two others were not included because of serious psychiatric illness and mental retardation. Thirty-five patients were excluded after inclusion. Three (1\%) were adopted and had no contact with their biological families and $32(10.1 \%)$ were unable to answer for themselves due to severe aphasia or coma. Participants had a mean age of $49.5(\mathrm{SD}=9.3)$ years, $68 \%$ were male and the majority had at least a high school education $(76 \%$, Table 1$)$. The mean number of siblings was 2.5 and 237 (92\%) patients had at least one sibling. No offspring stroke, CAD or PAD were reported. There were no significant differences in demographic data by sex, however there was a trend for age $(p=0.057)$, females were slightly younger than males (47.6 years vs. 50.4 years, respectively).

\section{Family history}

About 59\% of participants reported their father was deceased, while $36 \%$ reported a deceased mother $(\mathrm{p}<$ 0.001 , Table 1). Two patients did not know if their fathers were alive, and data regarding deceased parents was missing in four patients. Any first-degree $\mathrm{FH}$ of CVD was reported by 153 (59.5\%) patients. Most participants reported a first-degree FH of CAD (41\%), followed by stroke (34\%) and PAD (6\%). Patients reported relatively low numbers of disease and high proportions of 'don't know' in grandparents for all types of CVD (Table 2).

Table 1 Demographic data of the 257 patients included in the Stroke in the Young Study (NOR-SYS) in Bergen, Norway 2010-2014

\begin{tabular}{|c|c|c|c|c|}
\hline Variables & Total $\mathrm{N}=\mathbf{2 5 7}$ & Males $\mathrm{N}=175(68.1 \%)$ & Females $\mathrm{N}=82(31.9 \%)$ & $\mathbf{P}$ \\
\hline Age in years, mean (SD) & $49.5(9.3)$ & $50.4(8.5)$ & $47.6(10.6)$ & 0.057 \\
\hline Education & & & & 0.547 \\
\hline Basic school, n (\%) & $60(23.5)$ & $43(24.7)$ & $17(21.0)$ & \\
\hline High school, n (\%) & $91(35.7)$ & $64(36.8)$ & $27(33.3)$ & \\
\hline College/University, n (\%) & $104(40.8)$ & $67(38.5)$ & $37(45.7)$ & \\
\hline $\mathrm{N}$ of siblings, mean (SD) & $2.5(1.7)$ & $2.6(1.9)$ & $2.2(1.3)$ & 0.116 \\
\hline $\mathrm{N}$ of children, mean (SD) & $2.0(1.3)$ & $2.0(1.4)$ & $1.8(1.2)$ & 0.311 \\
\hline Deceased fathers, $n(\%)$ & $149^{*}(58.7)$ & $103(59.9)$ & $46(56.1)$ & 0.756 \\
\hline Deceased mothers, $n$ (\%) & $92^{\dagger}(36.4)$ & $60(35.1)$ & $32(39.0)$ & 0.542 \\
\hline First-degree FH of stroke, n (\%) & $87(33.9)$ & $55(31.4)$ & $32(39.0)$ & 0.230 \\
\hline First-degree $\mathrm{FH}$ of $\mathrm{CAD}, \mathrm{n}(\%)$ & $105(41.0)$ & $67(38.3)$ & $38(46.9)$ & 0.192 \\
\hline First-degree FH of PAD, n (\%) & $16(6.2)$ & $11(6.3)$ & $5(6.1)$ & 0.954 \\
\hline
\end{tabular}

Abbreviations: $S D$ standard deviation, $F H$ family history, First-degree $F H$ family history in parents, siblings or offspring, $C A D$ coronary artery disease, $P A D$ peripheral artery disease, $P$ p-value of comparison between males and females.

${ }^{*} \mathrm{~N}=254$ due to missing data in 5 of patients' fathers. ${ }^{\dagger} \mathrm{N}=252$ due to missing data in 4 of patients' mothers. 
Table 2 Reported family history of cardiovascular disease in first-degree relatives ${ }^{*}$ and grandparents of the 257 patients included in the Stroke in Young Study (NOR-SYS) in Bergen, Norway 2010-2014

\begin{tabular}{|c|c|c|c|c|}
\hline Relatives & Cardiovascular disease & Yes N (\%) & No N (\%) & Don't know N (\%) \\
\hline \multirow[t]{3}{*}{ Siblings $^{\dagger}$} & Stroke & $8(3.3)$ & $232(95.9)$ & $2(0.8)$ \\
\hline & Heart disease & $36(14.9)$ & $202(83.5)$ & $4(1.6)$ \\
\hline & PAD & $5(2.1)$ & $232(95.9)$ & $5(2.1)$ \\
\hline \multirow[t]{3}{*}{ Mothers } & Stroke & $46(17.1)$ & $202(78.6)$ & $9(3.5)$ \\
\hline & Heart disease & $55(21.6)$ & $187(73.3)$ & $13(5.1)$ \\
\hline & PAD & $9(3.5)$ & $233(90.7)$ & $15(5.8)$ \\
\hline \multirow[t]{3}{*}{ Fathers } & Stroke & $48(18.7)$ & $192(74.7)$ & $17(6.6)$ \\
\hline & Heart disease & $101(39.3)$ & $141(54.9)$ & $15(5.8)$ \\
\hline & PAD & $15(5.8)$ & $221(86.0)$ & $21(8.2)$ \\
\hline \multirow[t]{3}{*}{ Mothers' mothers } & Stroke & $30(11.7)$ & $143(55.9)$ & $83(32.4)$ \\
\hline & Heart disease & $35(13.7)$ & $126(49.2)$ & $95(37.1)$ \\
\hline & PAD & $1(0.4)$ & $180(70)$ & $76(29.6)$ \\
\hline \multirow[t]{3}{*}{ Mothers' fathers } & Stroke & $16(6.2)$ & $142(55.5)$ & $98(38.3)$ \\
\hline & Heart disease & $47(18.3)$ & $113(44.0)$ & $97(37.7)$ \\
\hline & PAD & $3(1.2)$ & $173(67.3)$ & $81(31.5)$ \\
\hline \multirow[t]{3}{*}{ Fathers' mothers } & Stroke & $20(7.8)$ & $120(46.7)$ & $117(45.5)$ \\
\hline & Heart disease & $21(8.2)$ & $121(47.1)$ & $115(44.7)$ \\
\hline & PAD & $5(1.9)$ & $167(65.0)$ & $85(33.1)$ \\
\hline \multirow[t]{3}{*}{ Fathers' fathers } & Stroke & $18(7.0)$ & $114(44.4)$ & $125(48.6)$ \\
\hline & Heart disease & $34(13.2)$ & $108(42.0)$ & $115(44.8)$ \\
\hline & PAD & $4(1.6)$ & $156(60.7)$ & $97(37.7)$ \\
\hline
\end{tabular}

Abbreviations: Stroke both ischemic events and intracranial hemorrhage, Heart disease including coronary artery disease and reported non-CAD such as heart failure, rhythm and/or valve problems, $P A D$ peripheral artery disease.

*No cardiovascular events were reported among offspring.

${ }^{\dagger} \mathrm{N}=242,242$ patients had one or more siblings.

\section{FH knowledge regarding type of CVD}

Patient reports on type of CVD in FDRs are summarized in Table 3. Patients reported more CAD among fathers than among mothers $(\mathrm{p}<0.001)$. Detailed knowledge regarding type of heart disease was high, whereas knowledge on type of parental stroke was lower. Comparing answers regarding disease type, 'don't know' type of stroke was significantly higher than 'don't know' type of heart disease for fathers $(\mathrm{p}<0.001)$, mothers $(\mathrm{p}<0.01)$, siblings $(\mathrm{p}=0.01)$, and all grandparents $(\mathrm{p}<0.001)$ except mothers' fathers $(p=0.5)$. Few patients reported a $\mathrm{FH}$ of PAD and the knowledge of ordinated treatment for PAD was not analyzed further.

\section{Sex differences in $\mathrm{FH}$}

There was a trend of more reported FH of CVD events and less frequent reporting of 'don't know' among females compared to males (Figure 1). When analyzing $\mathrm{FH}$ of CVD in grandparents, females reported significantly less 'don't know' regarding heart disease in mothers' mothers $(p=0.02)$ and of stroke in fathers' mothers $(\mathrm{p}=0.02)$. Patients reported 'Yes' or 'No' on FH of stroke in both parents in 235 (91\%) cases and having knowledge of both parents' FH was most common. Patients consistently reported less 'don't know' regarding maternal FH than paternal FH (Table 4). Males reported a mean number of 1.5 (SD: 1.28) family members with CVD, whereas females reported 1.9 (SD: 1.25; $\mathrm{p}=0.01$ ). Females reported a positive FH more often than males with an OR of 3.4 (95\% CI: 1.5 to 7.7; $\mathrm{p}<0.01$; Table 5). When analyzing a positive FH in FDRs only, females are more likely to report a positive FH with an OR of 2.5 (95\% CI: 1.3 to $4.8 ; \mathrm{p}<0.01$ ). In addition, increasing age was associated with a positive $\mathrm{FH}$ and higher educational category was associated with a negative $\mathrm{FH}$.

\section{Discussion}

We observed a high rate of reported CVD in patients' parents. The reported $\mathrm{FH}$ of parental stroke in the present study was $33 \%$, slightly lower than $41 \%$ reported in a Swedish study [9]. The reported 37\% FH of CAD in the present study is comparable with $38 \%$ in the Swedish study [9]. The slight disparity regarding parental stroke may be explained by the lower mean age of our patients 
Table 3 Comparing knowledge on type of cardiovascular disease in patients replying 'Yes' a family member suffered from stroke, heart disease and/or peripheral artery disease

\begin{tabular}{|c|c|c|c|c|c|c|c|}
\hline & Siblings ${ }^{*}$ & Mothers & Fathers & Mothers' mothers & Mothers' fathers & Fathers' mothers & Fathers' fathers \\
\hline Stroke & $N=8$ & $N=46$ & $N=48$ & $\mathrm{~N}=30^{\dagger}$ & $\mathrm{N}=16$ & $\mathrm{~N}=20$ & $\mathrm{~N}=18^{\dagger}$ \\
\hline TIA (\%) & $0(0.0)$ & $9(19.6)$ & $8(16.7)$ & $4(13.3)$ & $3(18.8)$ & $2(10.0)$ & $0(0.0)$ \\
\hline Cerebral infarction (\%) & $3(37.5)$ & $12(26.1)$ & $11(22.9)$ & $2(6.7)$ & $4(25)$ & $2(10.0)$ & $2(11.1)$ \\
\hline Cerebral bleeding (\%) & $1(12.5)$ & $7(15.2)$ & $5(10.4)$ & $1(3.3)$ & $2(12.5)$ & $1(5.0)$ & $0(0.0)$ \\
\hline Don't know (\%) & $4(50)$ & $18(39.1)$ & $24(50)$ & $23(76.7)$ & $7(43.8)$ & $15(75.0)$ & $16(88.9)$ \\
\hline Heart disease & $\mathrm{N}=36$ & $\mathrm{~N}=55^{+}$ & $\mathrm{N}=101^{\dagger}$ & $\mathrm{N}=35^{\dagger}$ & $\mathrm{N}=47^{+}$ & $N=21$ & $\mathrm{~N}=34^{+}$ \\
\hline Angina pectoris (\%) & $5(13.9)$ & $12(21.8)$ & $9(8.9)$ & $8(22.9)$ & $4(8.5)$ & $4(19.1)$ & $3(8.8)$ \\
\hline Myocardial infarction (\%) & $15(41.7)$ & $16(29.1)$ & $48(47.5)$ & $8(22.9)$ & $24(51.1)$ & $8(38.1)$ & $16(47.1)$ \\
\hline Non-CAD (\%) & $12(33.3)$ & $21(39.6)$ & $25(24.8)$ & $7(20)$ & $3(6.4)$ & $2(9.5)$ & $2(5.9)$ \\
\hline Don't know (\%) & $4(11.1)$ & $6(10.9)$ & $19(18.8)$ & $12(34.3)$ & $16(34.0)$ & $7(33.3)$ & $13(38.2)$ \\
\hline PAD & $\mathrm{N}=5^{+}$ & $N=9^{+}$ & $N=15$ & $N=1$ & $N=3$ & $\mathrm{~N}=5$ & $\mathrm{~N}=4$ \\
\hline Conservative (\%) & $2(40.0)$ & $3(33.3)$ & $2(13.3)$ & $0(0.0)$ & $0(0.0)$ & $1(20.0)$ & $0(0.0)$ \\
\hline Revascularization surgery (\%) & $2(40.0)$ & $1(11.1)$ & $5(33.3)$ & $1(100)$ & $0(0.0)$ & $0(0.0)$ & $0(0.0)$ \\
\hline Amputation (\%) & $0(0.0)$ & $0(0.0)$ & $2(13.3)$ & $0(0.0)$ & $3(100)$ & $2(40.0)$ & $1(25.0)$ \\
\hline Don't know (\%) & $1(20.0)$ & $5(55.6)$ & $6(40)$ & $0(0.0)$ & $0(0.0)$ & $2(40.0)$ & $3(75.0)$ \\
\hline
\end{tabular}

From the 257 patients included in the Stroke in Young Study (NOR-SYS) in Bergen, Norway 2010-2014.

Abbreviations: TIA transient ischemic attack, Non-CAD non-coronary heart disease, included heart failure, rhythm and/or valve problems.

${ }^{*} \mathrm{~N}=242,242$ patients had one or more siblings.

${ }^{\dagger}$ One answer regarding type of disease was missing and was imputed as don't know.

and the methodological differences concerning the acquisition of $\mathrm{FH}$, where we solely interviewed patients. The present study showed higher numbers of deceased fathers than mothers (149 vs. 92), probably caused by the higher life expectancy of females [25].
Earlier studies have observed a mother-daughter relationship in heredity of stroke [14]. Our results show that females are more likely to report a positive FH than males. Females reported a higher incidence of $\mathrm{FH}$ of CVD in total and had better knowledge on the type of

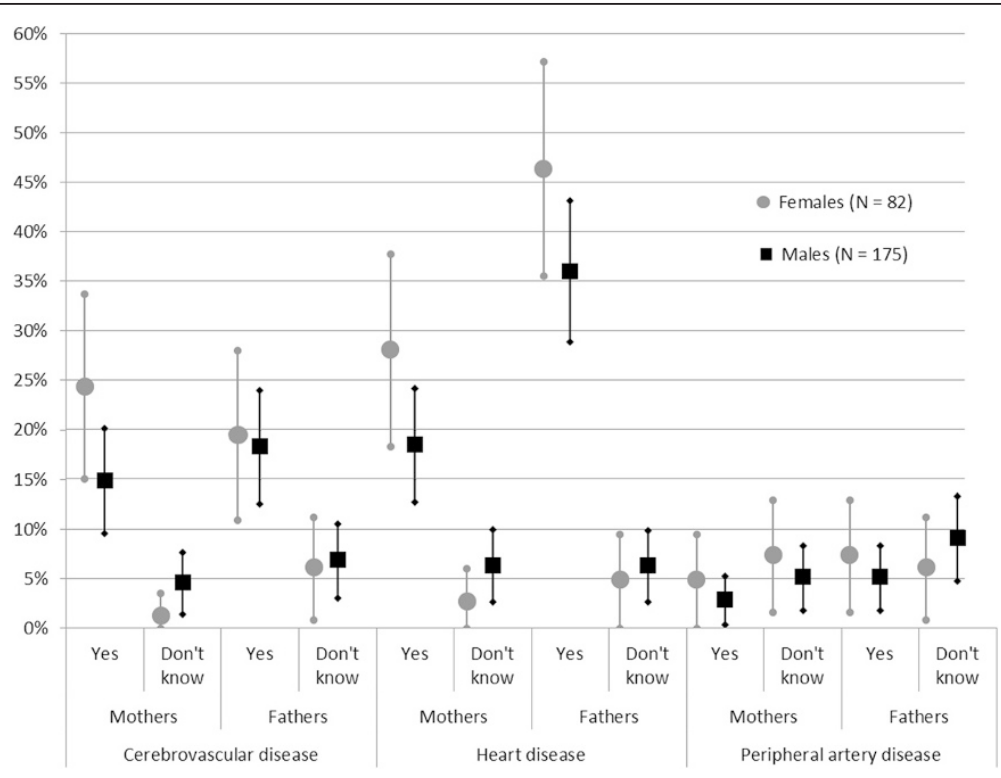

Figure 1 Reported parental history of cerebrovascular disease, coronary artery disease and peripheral artery disease from the 257 young and middle-aged ischemic stroke patients included in the Stroke in the Young Study (NOR-SYS) in Bergen, Norway 2010-2014, stratified by sex. Answers 'Yes' and 'Don't know' are displayed in percentage proportions with 95\% confidence intervals of the total $\mathrm{N}$, the remaining answering ' $N o$ '. 
Table 4 Comparing patients answering 'don't know' regarding family history of cardiovascular disease in maternal vs. paternal family members

\begin{tabular}{llll}
\hline $\begin{array}{lll}\text { Relatives } \\
\text { CVD }\end{array}$ & $\begin{array}{l}\text { Maternal } \\
\text { N (\%) }\end{array}$ & $\begin{array}{l}\text { Paternal } \\
\text { N (\%) }\end{array}$ & $\mathbf{P}^{*}$ \\
\hline Parent & & & \\
Stroke & $9(3.50)$ & $17(6.61)$ & 0.059 \\
CAD & $13(5.06)$ & $15(5.84)$ & 0.512 \\
PAD & $15(5.84)$ & $21(8.17)$ & 0.157 \\
Grandfathers & & & \\
Stroke & $98(38.13)$ & $125(48.64)$ & 0.000 \\
CAD & $81(31.52)$ & $97(37.74)$ & 0.006 \\
PAD & $97(37.74)$ & $115(44.75)$ & 0.024 \\
Grandmothers & & & \\
Stroke & $83(32.30)$ & $117(45.53)$ & 0.000 \\
CAD & $95(36.96)$ & $115(44.75)$ & 0.000 \\
PAD & $76(29.57)$ & $85(33.07)$ & 0.117 \\
\hline
\end{tabular}

From the 257 patients included in the Stroke in the Young Study (NOR-SYS) in Bergen, Norway 2010-2014.

Abbreviations: CVD Cardiovascular disease, Stroke both ischemic events and intracranial hemorrhage, $C A D$ coronary artery disease, $P A D$ peripheral artery disease.

"P-value calculated with McNemar's test.

CVD. In addition, both male and female patients know more about their maternal than paternal FH of CVD. Both sex of patient and maternal family linkage influence the response rate of 'don't know'; this suggests that knowledge of $\mathrm{FH}$ is strongly influenced by sex, possibly due to females being more involved in communication across generations in Norway. Additionally, the cultural designation of females as main family care-givers may enable them to obtain more information on FH of CVD [26].

Significant less reporting of 'don't know' regarding disease type in maternal vs. paternal grandparents supports the hypothesis that female-female communication on disease across generations increases knowledge on $\mathrm{FH}$. Another possible explanation for the higher maternal FH may be that males have a higher risk of violent death at young age, before CVD manifestations occur [27].
And the higher female reporting of FH may be explained by females with ischemic stroke simply having a higher $\mathrm{FH}$ of CVD burden than do males. However, these hypotheses do not explain the higher maternal than paternal FH also when comparing same-sex grandparents.

The patients reporting parental stroke had difficulties differentiating between the types of stroke, $40 \%$ and $50 \%$ of patients answered 'don't know' regarding mothers' and fathers' type of stroke, respectively. The present study was conducted 20 years after the introduction of MRI and we assumed that the new diagnostic and treatment opportunities in addition to informational campaigns would have improved patients' knowledge about stroke. Our reported numbers of parental ICH in relation to total stroke numbers were comparable to the relationship found in epidemiologic studies [28]. Patients seem to clearly recall a FH of ICH, but have more problems defining an ischemic stroke in their $\mathrm{FH}$. This may be due to higher mortality and often more dramatic symptoms of ICH [29]. It is reported that general knowledge on stroke is lower than knowledge on CAD, although the knowledge about stroke symptoms was not lower in newer studies [30,31]. Less reporting of 'don't know' on type of heart disease than on type of stroke regarding all FDRs in our study suggests less knowledge about stroke than CAD.

The reported FH of PAD was low in the present study; only $15(5.8 \%)$ of patients' fathers had PAD. In a recent Dutch study including 4700 patients with a history of cerebrovascular disease, CAD, PAD or aortic abdominal aneurysm, 16\% of patients had a FH of PAD, and they found that paternal PAD was a risk factor for subsequent PAD in the offspring [32]. This difference may be caused by the lower mean age of our patients, and that only patients with ischemic stroke were included in our study. However, the difference in prevalence of $\mathrm{FH}$ shows the importance of addressing all manifestation sites of atherosclerosis and vascular disease when evaluating $\mathrm{FH}$.

The reported FH of CVD among grandparents was low. The high reporting of 'don't know' regarding grandparents' FH of CVD and the almost absent knowledge of

Table 5 Logistic regression displaying factors possibly associated with a positive family history of cardiovascular disease of the 257 patients included in the Stroke in the Young Study (NOR-SYS) in Bergen, Norway 2010-2014

\begin{tabular}{|c|c|c|c|c|c|c|}
\hline \multirow{2}{*}{$\begin{array}{l}\text { Response variable: } \\
\text { Predictors }\end{array}$} & \multicolumn{3}{|c|}{ FH of FDR } & \multicolumn{3}{|c|}{ FH of FDR + grandparents } \\
\hline & OR & $95 \% \mathrm{Cl}$ & $\mathbf{P}$ & OR & $95 \% \mathrm{Cl}$ & $\mathbf{P}$ \\
\hline Sex (female) & 2.50 & $(1.31,4.78)$ & 0.005 & 3.37 & $(1.48,7.70)$ & 0.004 \\
\hline Education & 0.67 & $(0.47,0.98)$ & 0.038 & 1.20 & $(0.79,1.80)$ & 0.377 \\
\hline Number of siblings & 1.08 & $(0.9,1.27)$ & 0.329 & 0.99 & $(0.83,1.18)$ & 0.922 \\
\hline Age of patient (years) & 1.09 & $(1.0,1.13)$ & $<0.001$ & 1.03 & $(0.99,1.06)$ & 0.116 \\
\hline
\end{tabular}

Explanations and abbreviations: FH family history, FDR first-degree relatives, i.e. parents, siblings and offspring (no cardiovascular events were reported for offspring in this study), OR Odds ratio, $\mathrm{Cl}$ Confidence interval, Education basic school, high school and college/university: Number of siblings: 1 unit increase per sibling reported. 
grandparents' particular CVD type suggests this may be due to lack of knowledge on grandparental disease history and not absence of disease among grandparents. Less available medical care and less precise diagnostics may explain the lack of knowledge. In addition, the generation gap reduces information of grandparental $\mathrm{FH}$.

The present study is strengthened by the homogenous and well-defined study population, and also the detailed assessment of FH including CVD subtypes and the analysis of FH from several generations. The study also has some limitations. The well-defined study population of young ischemic stroke patients makes the results not directly generalizable to the general population. In addition, the self-reported FH may not be completely correct and is dependent on family relations, the patient cognitive status at time of the interview and several other factors. We excluded patients with aphasia and patients incapable of answering themselves, but we did not assess if severity of the acute disease could influence the answers regarding FH. However, the inclusion of 'don't know' as a possible answer increases the accuracy in providing a potential answer for patients unsure of their $\mathrm{FH}$.

\section{Conclusion}

In conclusion, the $\mathrm{FH}$ of CVD burden among young ischemic stroke patients was high. Females seem to have more knowledge on FH of CVD than do males, and knowledge on maternal $\mathrm{FH}$ is higher than paternal $\mathrm{FH}$. Knowledge on $\mathrm{FH}$ of heart disease type is significantly higher than type of stroke. We recommend obtaining the $\mathrm{FH}$ with the patient as the primary informant, however, the involvement of other family members may increase both the completeness and accuracy of the FH and should be encouraged. More public information on $\mathrm{FH}$ of CVD as a risk factor is warranted to improve the general knowledge of $\mathrm{FH}$ in the population. Information could be directed towards males in particular. As males have less knowledge regarding own $\mathrm{FH}$ than females; they have the most to gain by improving their FH knowledge. Increased knowledge of own $\mathrm{FH}$ provides an opportunity to take action to reduce risk and may encourage patients into smoking cessation, regular exercise and adopting a healthier diet. Increased attention on $\mathrm{FH}$ is important for the patient and also the public in general to improve this accessible, well-proven and inexpensive tool both for risk stratification and in aiding future genetic research.

\section{Competing interests}

The authors declare that they have no competing interests.

\section{Authors' contributions}

$H \varnothing$ participated in the design of the study, the data collection, performed the statistical analyses and drafted the manuscript. AF and KMS participated in the design of the study, the collection of data and critical revision of the manuscript. GEE participated in the statistical analyses and interpretation of results. $\mathrm{LT}$ and $\mathrm{HN}$ participated in the design of the study and critical revision of the manuscript. UWA conceived of the study, and participated in its design and coordination, the data collection and critical revision of the manuscript. All authors read and approved the final manuscript.

\section{Acknowledgements}

We thank Jeanette Haveland Antoniazzi and study Nurse Linn Elin Rødal for invaluable help in administering the NOR-SYS study.

\section{Author details}

${ }^{1}$ Department of Clinical Medicine, University of Bergen, Bergen, Norway. ${ }^{2}$ Department of Neurology, Haukeland University Hospital, N-5021 Bergen, Norway. ${ }^{3}$ Centre for Clinical Research, Haukeland University Hospital, Bergen, Norway. ${ }^{4}$ Lifestyle Epidemiology Research Group, Department of Global Public Health and Primary Care, University of Bergen, Bergen, Norway.

Received: 13 November 2014 Accepted: 20 February 2015

Published online: 12 March 2015

\section{References}

1. Banerjee A. A review of family history of cardiovascular disease: risk factor and research tool. Int J Clin Pract. 2012;66(6):536-43. doi:10.1111/j.17421241.2012.02908.x.

2. Lloyd-Jones DM, Nam BH, D’Agostino Sr RB, Levy D, Murabito JM, Wang TJ, et al. Parental cardiovascular disease as a risk factor for cardiovascular disease in middle-aged adults: a prospective study of parents and offspring. JAMA. 2004;291(18):2204-11. doi:10.1001/jama.291.18.2204.

3. Jousilahti P, Puska P, Vartiainen E, Pekkanen J, Tuomilehto J. Parental history of premature coronary heart disease: an independent risk factor of myocardial infarction. J Clin Epidemiol. 1996;49(5):497-503.

4. Colditz GA, Rimm EB, Giovannucci E, Stampfer MJ, Rosner B, Willett WC. A prospective study of parental history of myocardial infarction and coronary artery disease in men. Am J Cardiol. 1991;67(11):933-8.

5. Sesso HD, Lee IM, Gaziano JM, Rexrode KM, Glynn RJ, Buring JE. Maternal and paternal history of myocardial infarction and risk of cardiovascular disease in men and women. Circulation. 2001;104(4):393-8. doi:10.1161/ hc2901.093115.

6. Pandey AK, Pandey S, Blaha MJ, Agatston A, Feldman T, Ozner M, et al. Family history of coronary heart disease and markers of subclinical cardiovascular disease: where do we stand? Atherosclerosis. 2013;228 (2):285-94. doi:10.1016/j.atherosclerosis.2013.02.016.

7. Jousilahti P, Rastenyte D, Tuomilehto J, Sarti C, Vartiainen E. Parental history of cardiovascular disease and risk of stroke : a prospective follow-up of 14 371 middle-aged men and women in Finland. StrokeJ Cerebral Circ. 1997;28 (7):1361-6. doi:10.1161/01.str.28.7.1361.

8. Flossmann E, Schulz UG, Rothwell PM. Systematic review of methods and results of studies of the genetic epidemiology of ischemic stroke. StrokeJ Cerebral Cir. 2004;35(1):212-27. doi:10.1161/01.STR.0000107187.84390.AA.

9. Jood K, Ladenvall C, Rosengren A, Blomstrand C, Jern C. Family history in ischemic stroke before 70 years of age: the Sahlgrenska Academy Study on Ischemic Stroke. Stroke. 2005;36(7):1383-7. doi:10.1161/01. STR.0000169944.46025.09.

10. Seshadri S, Beiser A, Pikula A, Himali JJ, Kelly-Hayes M, Debette S, et al. Parental occurrence of stroke and risk of stroke in their children: the Framingham study. Circulation. 2010;121(11):1304-12. doi:10.1161/ CIRCULATIONAHA.109.854240.

11. Bak S, Gaist D, Sindrup SH, Skytthe A, Christensen K. Genetic liability in stroke: a long-term follow-up study of Danish twins. Stroke. 2002;33(3):769-74.

12. Meschia JF, Nalls M, Matarin M, Brott TG, Brown Jr RD, Hardy J, et al. Siblings with ischemic stroke study: results of a genome-wide scan for stroke loci. StrokeJ Cerebral Circ. 2011;42(10):2726-32. doi:10.1161/STROKEAHA.111.620484.

13. Kasiman K, Lundholm C, Sandin S, Malki N, Sparen P, Ingelsson E. Familial effects on ischemic stroke: the role of sibling kinship, sex, and age of onset. Circ Cardiovasc Genet. 2012;5(2):226-33. doi:10.1161/CIRCGENETICS.111.962241.

14. Touze $E_{1}$ Rothwell PM. Sex differences in heritability of ischemic stroke: a systematic review and meta-analysis. StrokeJ Cerebral Circ. 2008;39(1):16-23. doi:10.1161/STROKEAHA.107.484618.

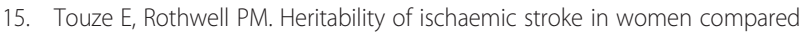
with men: a genetic epidemiological study. Lancet Neurol. 2007;6(2):125-33. doi:10.1016/S1474-4422(06)70683-4. 
16. Reeves MJ, Bushnell CD, Howard G, Gargano JW, Duncan PW, Lynch G, et al. Sex differences in stroke: epidemiology, clinical presentation, medical care, and outcomes. Lancet Neurol. 2008;7(10):915-26. doi:10.1016/S1474-4422 (08)70193-5.

17. Flossmann E, Rothwell PM. Family history of stroke does not predict risk of stroke after transient ischemic attack. StrokeJ Cerebral Circ. 2006;37(2):544-6. doi:10.1161/01.STR.0000198879.11072.f2.

18. Siegerink B, Rosendaal FR, Algra A. Family history differs between young women with myocardial infarction and ischemic stroke: results from the RATIO case-control study. Atherosclerosis. 2012;223(1):235-8. doi:10.1016/j. atherosclerosis.2012.04.024

19. Kennedy RE, Howard G, Go RC, Rothwell PM, Tiwari HK, Feng R, et al. Association between family risk of stroke and myocardial infarction with prevalent risk factors and coexisting diseases. StrokeJ Cerebral Circ. 2012;43 (4):974-9. doi:10.1161/STROKEAHA.111.645044.

20. Lisabeth LD, Smith MA, Brown DL, Uchino K, Morgenstern LB. Family history and stroke outcome in a bi-ethnic, population-based stroke surveillance study. BMC Neurol. 2005;5:20. doi:10.1186/1471-2377-5-20.

21. Wintermark M, Sanelli PC, Albers GW, Bello J, Derdeyn C, Hetts SW, et al. Imaging recommendations for acute stroke and transient ischemic attack patients: a joint statement by the American Society of Neuroradiology, the American College of Radiology, and the Society of Neurolnterventional Surgery. Am J Neuroradiol. 2013;34(11):E117-27.

22. Rasura M, Baldereschi M, Di Carlo A, Di Lisi F, Patella R, Piccardi B, et al. Effectiveness of public stroke educational interventions: a review. Eur J Neurol. 2014:21(1):11-20. doi:10.1111/ene.12266.

23. Guttmacher AE, Collins FS, Carmona RH. The family history-more important than ever. N Engl J Med. 2004;351(22):2333-6. doi:10.1056/NEJMsb042979.

24. Fromm A, Thomassen L, Naess H, Meijer R, Eide GE, Krakenes J, et al. The Norwegian Stroke in the Young Study (NOR-SYS): rationale and design. BMC Neurol. 2013;13(1):89. doi:10.1186/1471-2377-13-89.

25. Statistics Norway. Population life expectancy. Statistics Norway. http://ssb. no/en/befolkning/statistikker/dode. Published: 8 April 2014. Accessed: 26 June 2014.

26. Finch J, Groves D. Community care and the family: a case for equal opportunities? J Soc Policy. 1980;9(04):487-511.

27. Næss $\varnothing$, Strand BH, Smith GD. Childhood and adulthood socioeconomic position across 20 causes of death: a prospective cohort study of 800000 Norwegian men and women. J Epidemiol Community Health. 2007;61 (11):1004-9.

28. Donnan GA, Fisher M, Macleod M, Davis SM. Stroke. Lancet. 2008;371 (9624):1612-23. doi:10.1016/S0140-6736(08)60694-7.

29. Andersen KK, Olsen TS, Dehlendorff C, Kammersgaard LP. Hemorrhagic and ischemic strokes compared: stroke severity, mortality, and risk factors. Stroke J Cerebral Circ. 2009;40(6):2068-72. doi:10.1161/STROKEAHA.108.540112.

30. Christian AH, Rosamond W, White AR, Mosca L. Nine-year trends and racial and ethnic disparities in women's awareness of heart disease and stroke: an American Heart Association national study. J Womens Health. 2007;16(1):68-81. doi:10.1089/jwh.2006.M072.

31. Gill R, Chow CM. Knowledge of heart disease and stroke among cardiology inpatients and outpatients in a Canadian inner-city urban hospital. Can J Cardiol. 2010;26(10):537-40.

32. Weijmans $M$, van der Graaf $Y$, De Borst GJ, Nathoe HM, Algra A, Visseren FL. Parental history and the risk of subsequent vascular events in patients with clinically manifest vascular disease: the effects of sex of the parent and vascular disease location. Atherosclerosis. 2014;234(1):129-35.

\section{Submit your next manuscript to BioMed Central and take full advantage of:}

- Convenient online submission

- Thorough peer review

- No space constraints or color figure charges

- Immediate publication on acceptance

- Inclusion in PubMed, CAS, Scopus and Google Scholar

- Research which is freely available for redistribution 